\title{
Aproximaciones a las nociones del territorio: ciudad, sentidos, mapas e imaginarios
}

\section{Artículo de revisión}

\section{Yulieth Guerrero Nieto}

Fundación Universitaria Juan de Castellanos, Colombia yuliguerreronieto@gmail.com

\section{Carlos Mario Rodríguez}

Universidad de Boyacá, Colombia

carrodriguez@uniboyaca.edu.co

$-$

Recibido: 15 de mayo de 2018

Aprobado: 20 de junio de 2018

Cómo citar este artículo: Guerrero Nieto, Yulieth; Rodríguez, Carlos Mario (2019). Aproximaciones a las nociones del territorio: ciudad, sentidos, mapas e imaginarios. Calle 14: revista de investigación en el campo del arte 14(25), pp. 188-204. DOI: https://doi. org/10.14483/21450706.14076

\section{(2) (1)}

https://creativecommons.org/licenses/by/4.0/deed.es 
Aproximaciones a las nociones del territorio: ciudad, sentidos, mapas e imaginarios

\title{
Resumen
}

El presente artículo de revisión surge del interés de los investigadores por el estudio de la ciudad entendida desde su dimensión intangible como territorio sensorial y perceptivo. De esta manera, se hace imperativa la revisión de referentes metodológicos, conceptuales y estéticos que permitan contextualizar el tema, articular los avances que hasta el momento se han desarrollado y determinar las diferentes categorías de análisis del mismo, para ser aplicados especialmente en las ciudades intermedias. En el texto, se abordan referentes que en primer lugar han estudiado la percepción sensorial de la ciudad como mecanismo generador de imaginarios urbanos, y, en segundo lugar, el mapa, entendido como herramienta de materialización gráfica y visual de los fenómenos analizados en la interacción y apropiación del ciudadano con la ciudad. Todo ello, encaminado a la construcción y compresión de la imagen de la ciudad como territorio vivido por el habitante.

\section{Palabras claves}

Espacio urbano; imaginario; mapa; percepción; territorio; significado

Approaches to the Notions of the Territory: City, Senses, Maps and Imaginaries

\begin{abstract}
The present review article arises from the interest of researchers for the study of the city understood from its intangible dimension as a sensory and perceptive territory. Thus, it is imperative to review methodological, conceptual and aesthetic referents that allow the subject to be contextualized, articulate the advances that have been developed so far and determine the different categories of analysis to be applied, especially in intermediate cities. We reference sources that have studied the sensorial perception of the city as a generating mechanism of urban imaginaries and, secondly, the map, understood as a tool for visual and graphic materialization of the phenomena analyzed in the interaction and appropriation of the citizen with the city. All this is aimed at the construction and compression of the image of the city as a territory lived by the inhabitant.
\end{abstract}

\section{Keywords}

Urban space; imaginary; map; perception; territory; meaning

\section{Résumé}

Le présent article de revue découle de l'intérêt des chercheurs pour l'étude de la ville comprise dans sa dimension immatérielle comme territoire sensoriel et perceptif. Il est donc impératif de passer en revue les référents méthodologiques, conceptuels et esthétiques permettant de contextualiser le sujet, d'articuler les avancées développées jusqu'à présent et de déterminer les différentes catégories d'analyses à appliquer notamment dans les villes intermédiaires. Nous référençons des sources qui ont étudié la perception sensorielle de la ville en tant que mécanisme générateur d'imaginaires urbains et, d'autre part, la carte, considérée comme un outil de matérialisation visuelle et graphique des phénomènes analysés dans l'interaction et l'appropriation du citoyen avec la ville. Tout cela visait à la construction et à la compression de l'image de la ville en tant que territoire vécu par ses habitants.

\section{Mots clés}

Espace urbain; imaginaire; carte; perception; territoire; sens 
Abordagens às noções do território: cidade, sentidos, mapas e imaginários

\section{Resumo}

O presente artigo de revisão surge do interesse de pesquisadores pelo estudo da cidade compreendida a partir de sua dimensão intangível como território sensorial e perceptivo. Assim, é imperativo revisar referencias metodológicas, conceituais e estéticas que permitam contextualizar o sujeito, articular os avanços desenvolvidos até o momento e determinar as diferentes categorias de análise a serem aplicadas especialmente em cidades intermediárias. Faz-se referência a fontes que estudaram a percepção sensorial da cidade como mecanismo gerador de imaginários urbanos e, em segundo lugar, o mapa, entendido como ferramenta de materialização visual e gráfica dos fenômenos analisados na interação e apropriação do cidadão com o município. Tudo isso, visando a construção e compressão da imagem da cidade como território vivido pelo morador.

\section{Palavras-chaves}

Espaço urbano; imaginário; mapa; percepção; território; significado

\section{Maillallachiska}

Kai kawachii iagtaka kami, kai kaiarimi chi runa tapug purigkuna i achaikungapa chi sug atun puglupi imasami uiarimi i imasami kawarii. Chasaiatata tukumi ka kawachiikuna imasa ruraska, imasa kilkaska chasami kawangakuna maikamami ruraska kankuna ashai u ashka ruraskakuna. Chasami kai iachaikuikuna iachachingakuna sugma sugama atun puglukunama. Kai kilkaska kaiarimi maimandami kaiariri, uiaspa sug atun puglupi i ña chaiaiatata kami kai ruraikuna kawaspa sugama sugma kai runakunata kai runakunata kai atun puglumanda kaskata. Kai tukuirimi ruraspa i kawachispa kai atun puglumadaiatata imasami kaugsankuna kai runakuna.

\section{Rimangapa Ministidukuna}

Luarsina tiaska sug puglupi, iuiarikuna, alpa kilkaska alpa; kawachii, alpa; ima niriagta 


\section{La ciudad y el territorio}

El interés que generan los procesos de desarrollo de las ciudades han dejado en evidencia la multiplicidad de disciplinas para las que el entorno urbano es un objeto de estudio válido, es así como desde la comunicación, el diseño, la psicología y el arte, entre muchos otros, se han desarrollado proyectos cuyo objetivo en común ha sido el de articular una visión de la ciudad. Precisamente, ha sido el estudio de la imagen de la ciudad como reflejo de la cultura e identidad de sus habitantes lo que ha llevado a esta revisión, en la que se comprende que la naturaleza interdisciplinar de este tipo de investigaciones, incluye el concepto de ciudad como territorio, y lo interpreta como escenario de significación que se construye desde la experiencia del ciudadano y su interacción con el contexto.

El territorio en sentido general, expresa la relación del hombre con el planeta, esa relación se da en términos funcionales y, sobre todo, en términos de significación, así, ocupación, grupo, conexión, información, posesión, se relacionan con lo que puede entenderse como territorio, de manera que:

Los territorios son las manifestaciones o expresiones de la relación inseparable y continuamente cambiante entre la especie humana y la tierra. Dicho de otra manera, los territorios son, en el momento en que significan algo para alguien, es decir, en el momento en que un grupo social, una «comunidad» o un grupo con intereses comunes, escribe sobre la tierra sus formas de morar. $\{\ldots\}$ La especie humana se caracteriza, especialmente, porque sus significaciones territoriales son simbólicas. (Noguera, 2004, p. 117)

El territorio urbano, puede entenderse primariamente como el espacio físico que ocupa la ciudad, sin embargo, el concepto territorio alberga muchas características que sobrepasan lo meramente físico y geográfico y permiten ampliar por tanto su definición; la ciudad como territorio urbano implica una serie de relaciones tejidas a través de redes que permiten la vida colectiva y el funcionamiento de la misma en el marco del espacio físico, pero también del espacio simbólico, se producen entonces en la ciudad micro territorios que se van articulando a otros macro, justamente a partir de redes de conexión, redes físicas y tangibles, pero sobre todo a redes relacionales, tal como lo explica Joseph (2001): redes de sociabilidad, redes de comunicación y redes de transacciones. Montoya (2000) explica que los territorios geográficos constituyen la primera capa de escritura de las culturas, de ahí que los territorios estén conformados de capas que se sobreponen y traslapan en donde es claro que los territorios simbólicos se constituyen mucho más de la geograficidad y que por tanto la geografía funciona como un palimpsesto cultural. Pérgolis, expresa entonces que "hay tantas concepciones del territorio como puntos de vista tengamos y como informaciones de él podamos recibir" (1998, p. 37).

El territorio, es, por tanto, un "elemento substancial de cohesión de la nación, referente indispensable para individuos y colectividades sociales, generador de significados e imaginarios colectivos y propulsor de la construcción de tejido social y de la socialización primaria." (Montañez, 2002), de allí que en el reconocimiento de referencias, signos y símbolos espaciales esté cifrado el sentido y grados de apropiación del territorio como conjunto de pluralidades. La concepción del territorio, más allá, de lo físico hace comprensible la idea de que "el lugar donde vivimos o donde aprendemos o desde donde vemos el mundo sufre importantes transformaciones. La más importante para el entorno urbano es quizá que la vida y sus territorios ya no se asocian a un espacio físico concreto" (Silva, 2002, p. 110).

Se podría comprender entonces la noción de territorio como el lugar de la identidad cultural (Auge, 1993, p. 54) y espacial, un espacio objetivo y subjetivo de significaciones, comunicaciones y relaciones; un lugar histórico y en continua transformación.

\section{Revisión metodológica sobre experiencias sensoriales del territorio urbano}

La experiencia de habitar un territorio, se gesta de manera primaria en la interacción sensorial del habitante con su entorno, de allí, surge el concepto de paisaje sensorial, un término con diversos usos e interpretaciones en la música, el arte y la antropología, pero, con el propósito en común de caracterizar el territorio a partir de la comunicación entre el contexto urbano y el habitante por medio de los sentidos.

El paisaje sensorial se define como el conjunto de estímulos sensoriales que emite un contexto urbano que contribuye a la conformación de una imagen mental del entorno a partir de las percepciones del habitante, de acuerdo a Ross (2014), "nuestra comprensión del paisaje refleja nuestro emplazamiento dentro de él como seres sociales y fenomenales". Así pues, las 
percepciones sensoriales hacen posible la conformación de una imagen mental del espacio, de igual forma, las relaciones de las personas con el entorno son, en gran parte, culturales en tanto reflejo de las costumbres de la comunidad.

Es posible identificar un amplio rango de experiencias investigativas desde la percepción sensorial, como Bogotá, cinco sentidos (Salas, Ávila, y Quiroz, 2003) que desarrolló una interpretación de la ciudad de Bogotá, en la que un grupo interdisciplinar de artistas e investigadores caracterizó la capital colombiana desde una narrativa que conjugó la descripción escrita con la interpretación visual. Bajo la misma línea investigativa, actúa el colectivo colombiano, Popular de Lujo (2000) quienes llevan más de una década registrando la gráfica popular de la ciudad de Bogotá, así como de algunas partes de Colombia; actualmente agrupan en su archivo, fotografías y estudios inspirados en la cultura popular e identidad colombiana. El mencionado colectivo, apuesta por investigaciones que abordan la identidad local expresada en la cotidianidad y costumbres del ciudadano desde un enfoque que aunque es generalmente visual llega a abordar otro tipo de sentidos, por ejemplo, se hace referencia a trabajos como Mesa 19, exploración fotográfica de la estética de los restaurantes del centro de la ciudad de Bogotá (Popular de Lujo, 2000), y Eres lo que comes (2000) estudio de carácter experimental de gestión urbana e interacción cultural sobre la iconografía de los avisos de las comidas rápidas en Bogotá.

Una de las herramientas empleadas con mayor frecuencia y eficacia en este tipo de estudios es la fotografía, que más allá de técnica de registro permite realizar una radiografía del momento histórico en el que fue realizada la captura. A propósito del desarrollo fotográfico, New York Vertical (2001), hace una interpretación visual de la ciudad de Nueva York a partir del concepto de la verticalidad, de esta manera, presenta un recorrido urbano a través de diferentes enfoques y lugares que siempre mantienen la verticalidad en el registro fotográfico. Es significativo, que el tratamiento del encuadre como hilo conductor de la verticalidad característica de Nueva York, se traduce a una forma particular de concebir la ciudad. Metamorfosis de una ciudad (Museo de Bogotá, 2005), es uno de los trabajos fotográficos de Paul Beer en Bogotá, que desarrolla un discurso en torno a la mirada particular del fotógrafo y a su percepción del entorno que de manera similar a New York Vertical, se fundamenta en la técnica fotográfica empleada y constituye además un lenguaje particular del autor. Sin embargo, a diferencia del trabajo de Hamann, Paul Beer no presenta a Bogotá como una muestra del instante, sino como un viaje a través del tiempo y de las transformaciones que sufre la ciudad con el paso de los años.

El abordaje a la ciudad desde la visualidad es el más frecuente entre los estudios revisados, sin embargo sentidos como el olfato y el gusto constituyen nuevas propuestas que emergen en diversos lugares alrededor del mundo; Armando Silva (2003) articula desde el estudio de los imaginarios urbanos de la ciudad de Bogotá una lectura de los aromas que se esparcen en la capital y reflexiona acerca de la evolución de los ritos cotidianos de los bogotanos y de los cambios que sufren las costumbres de los ciudadanos con el tiempo, en la medida en que estas se adaptan a nuevos escenarios. Asimismo, indaga sobre las percepciones de miedo y gusto en la ciudad a partir de la relación de lugares y sentidos, de esta manera, se desarrolla un croquis urbano de los olores de Bogotá, en el que los malos olores tienden a relacionarse, por ejemplo, con el peligro y la pobreza representados por lugares como El Cartucho, la zona industrial y la venta de comidas callejeras.

Kate McLean (2014), ha enfocado sus estudios en el descubrimiento de las narrativas de lugar que se esconden desde la perspectiva de los cinco sentidos, en sus trabajos, la cartografía es la herramienta que establece la conexión entre las percepciones sensoriales y el entorno urbano. Uno de los trabajos con mayor impacto de McLean es la creación del Mapa de los aromas de París, una estrategia didáctica para explorar la ciudad y crear un nuevo mapa de París a partir de las experiencias personales que pueden llegar a evocar los olores de una ciudad; se elaboró un mapa con los aromas que caracterizan a París y las narrativas de lugares con las que se relacionan con los mismos, y se estableció que un sentido como el olfato, en particular tiene una estrecha relación con la memoria y las sensaciones de agrado o rechazo por determinadas zonas de una ciudad.

El Periódico El Tiempo (2014), desarrolló una experiencia, en la que periodistas y expertos en química de olores realizaron un trabajo de campo a partir de la pregunta ¿A qué huele Bogotá?, de esta manera, la visita a 8 sectores concurridos de la ciudad llevó a la caracterización de un paseo olfativo. De manera similar, Páez y Hernández (2014), en el documental Son tus aromas: Bogotá, realizaron un recorrido por seis lugares de la capital para identificar aromas y sensaciones como los olores de pino y tierra húmeda en el Parque 
Nacional o aromas de incienso y madera en la Iglesia de Santa Clara, entre otros, una experiencia en la que se demuestra que el sentido del olfato vincula emocionalmente con los lugares, por medio de los buenos o malos olores y que el ciudadano establece preferencias y rechazos, asociaciones a miedo y seguridad y relaciones socioeconómicas en el entorno.

La riqueza gastronómica propia de las ciudades latinoamericanas ha posibilitado investigaciones generalmente de carácter antropológico y social que se han propuesto la documentación y rescate de los sabores y saberes culturales; en Barcelona, se llevó a cabo Food cultura (2011), un proyecto, en el cual se ha desarrollado una colección de objetos y experiencias que dan cuenta de intervenciones, actividades y proyectos realizados en torno a la relación de la gastronomía con la cultura, con el objetivo de rescatar las tradiciones locales y autóctonas; para Miralda, el rito que permite compartir la comida es uno de los dominios esenciales de la cultura, más que una obra artística, el proyecto constituye una recopilación poética de la memoria y acervo cultural de las sociedades por medio de los sabores locales.

En el contexto local se han desarrollado también exploraciones en esta categoría sensorial, Entre lo puro e impuro representaciones iconográficas de Bogotá (2012), desarrolla una compilación y análisis de cinco expresiones gráficas de la ciudad de Bogotá, una de ellas titulada Metáforas e íconos de la carne en Bogotá (2010), analiza la representación de los productos de consumo derivados de la carne, en la gráfica popular. La investigación sintetiza el análisis de las representaciones gráficas encontradas en los avisos de establecimientos de venta de carne (res, cerdo, pollo, pescado) en el centro de la ciudad de Bogotá y plantea lecturas de imaginarios y aspectos sociales reflejados y connotados en dichas representaciones.

Con relación al sentido del tacto, la investigación, Expresiones estéticas del hábitat dentro de una comunidad barrial en transformación: La piel del Morro, (Echeverri Arango, 2007) se dedica al estudio de la 'piel de la ciudad' entendida esta desde la apropiación que hacen los habitantes por el espacio (paredes, fachadas, cuadras, senderos) y las manifestaciones estéticas que surgen en el mismo y que hacen parte de la necesidad de las personas por humanizar el entorno, se realiza una mirada, desde la estética, a la configuración del paisaje urbano del barrio Moravia en los sectores de El Morro y El Oasis en la ciudad de Medellín, caracterizado por ser un contexto formado en torno a la 'montaña de basura' principal fuente de ingreso de sus habitantes en el ejercicio del reciclaje. La mirada se da a partir de la relación que existe entre las prácticas culturales de los ciudadanos y la apropiación y construcción misma del entorno, particularmente en este sector de invasión que ha surgido desde la basura y ha ido construyendo hogares en un sector de difíciles condiciones geográficas, sociales y ambientales: la piel de la montaña ha sido humanizada en la práctica de un bricolaje que constantemente muta en construcciones que crecen o se destruyen, en una arquitectura del desecho que forma un collage de materiales y formas que está más allá de conceptos como 'bonito' o 'feo' porque la principal motivación de quienes lo construyen es la supervivencia. Esta apreciación de la realidad humana revela como mediante una apreciación estética es posible identificar la cotidianidad de un grupo de habitantes, sus prácticas, comportamientos y costumbres y como este tipo de manifestaciones revelan nociones del gusto de sus habitantes y maneras habitar, expresarse y apropiarse del espacio.

Esta noción estética del entorno, lleva a cuestionarse por el tema del color de la ciudad, aspecto concerniente al sentido de la vista y que en cierta medida constituye la textura de la imagen urbana, al respecto, existen grandes experiencias analíticas alrededor del mundo; sin duda, uno de los referentes principales es Phillipe Lenclos, con Colors of the World (1999), una compilación del trabajo desarrollado bajo la teoría de la 'Geografía del color', que propone que cada ciudad es poseedora de una información cromática que la hace única y está directamente relacionada con su patrimonio cultural e histórico, es decir que el color de las ciudades es un reflejo del momento que viven sus habitantes, de su pasado y proyección a futuro. Cada territorio posee unos valores cromáticos que son reflejo de su identidad y cultura, que pueden ser sintetizados en paletas de color que permiten realizar una caracterización territorial por medio del color.

\section{En A perceptual approach to the urban color reading} (Boeri, 2010) se establece que para desarrollar una interpretación cromática de un lugar es necesario considerar dos variables: los colores aleatorios, que se refieren a los elementos cambiantes en la imagen urbana que tienen que ver con los cambios de luz, estación y evento $y$, los colores permanentes, referidos a los elementos estables en la ciudad, como las fachadas, el mobiliario urbano y el paisaje. 


\section{ESTUDIOS DEL COLOR URBANO}

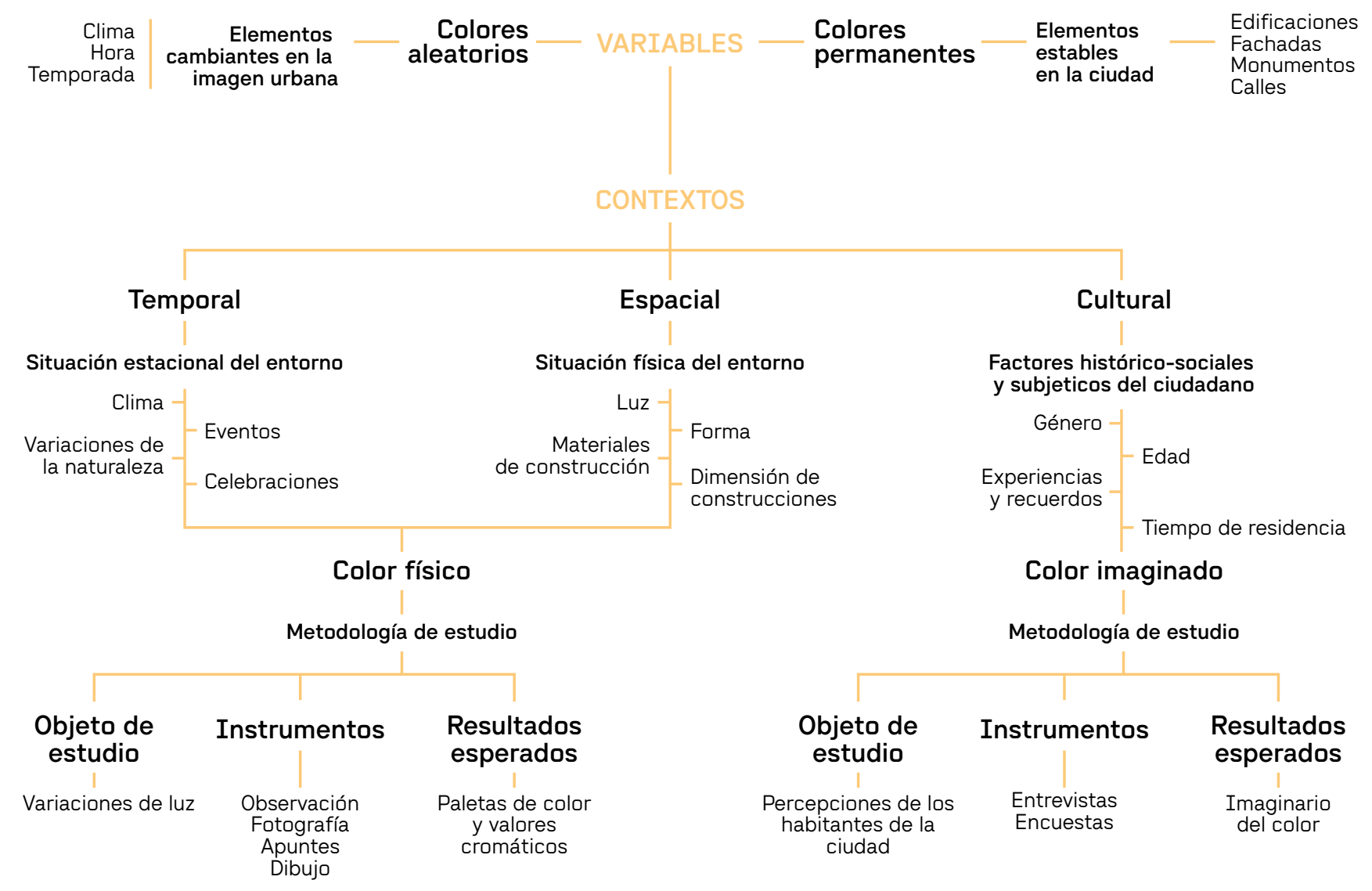

Gráfica 1. Mapa conceptual del proceso de estudio del color urbano. Fuente: Rodríguez (2014).

En los análisis cromáticos urbanos intervienen, por un lado, los contextos temporal y espacial que tienen que ver con la situación estacional y física del entorno, que finalmente se traducen al estudio del color físico, en el que el objeto de estudio son las fachadas, el paisaje, los momentos del día y las variaciones de luz, analizados a partir de instrumentos y técnicas como la observación, la fotografía y los apuntes de dibujo, y que conduce a resultados como la conformación de paletas de color y valores cromáticos. Por otro, el contexto cultural aborda el color desde la perspectiva del ciudadano, en la que intervienen factores histórico-sociales y subjetivos que se expresan en el color imaginado, cuyo objeto de estudio son las percepciones de los habitantes de la ciudad, que lleva finalmente, a la estructuración del color imaginado.

En Colombia, Los colores de la calle (Saldarriaga, 1985) y Patrones de color - Interpretación visual de los valores cromáticos regionales de Caldas (Gómez, 2006) son referentes importantes en el tema del color; en el primer caso, los colores constituyen una búsqueda de los valores cromáticos de los pueblos de Colombia a partir del estudio de las fachadas de las casas de los barrios populares de algunas ciudades del país, allí se descubre por medio del color y la arquitectura popular, la apropiación que hacen las personas por el espacio y cómo la fachada es un reflejo de la cultura, la historia y la expresión del pueblo, en el que el color es el lazo que une estos componentes y los hace más evidentes.

En el segundo caso, se hace un estudio que aplica la teoría del color en un contexto social, los municipios del departamento de Caldas. Esta búsqueda, relaciona la información visual con el valor cromático identificado en el paisaje, la arquitectura y la expresión popular regional. El registro es sistematizado a partir de la configuración de paletas de color correspondientes a cada municipio, de esta forma se plantea un uso del color de acuerdo al contexto y a la identidad de cada lugar.

En el contexto local, se ha adelantado el proyecto Cromatología de la ciudad imaginada/Tunja (Rodríguez, 2013), que hace parte de una serie de acercamientos 
a la ciudad de Tunja, desde los imaginarios urbanos, la imagen de la ciudad y la percepción del ciudadano, en este caso, el proyecto caracteriza la ciudad de Tunja desde la percepción cromática de los ciudadanos comparada con los valores cromáticos de la ciudad y plantea una lectura del contexto que inicialmente se tradujo a paletas de color, pero que a partir del análisis permitió develar una imagen de la ciudad que constituye las dinámicas, formas de actuar y apropiación de los ciudadanos frente a su entorno urbano.

Con relación a las percepciones sonoras, Daniel Goldaracena (2013) en Ciudad de México, desarrolló durante los años 2010 y 2012, un ejercicio exploratorio, en el que, a partir de recorridos y visitas a los barrios más representativos de la capital, capturó paisajes sonoros e instantes de la cotidianidad representados en los sonidos. De esta manera, el proyecto mostró cómo a través del sonido se,

Captura el peso de lo local [...] desde los trinos de los cientos de pájaros que al atardecer se resguardan en las copas de los árboles del Parque del Reloj en Polanco, hasta las alabanzas en honor a La Santa Muerte en el barrio de Tepito, pasando por el merolico que describe las bondades de una pomada para los pies, en el mercado de La Merced. (Altamirano, 2013)

Igualmente, el 'Book of Sounds' (Fonoteca Nacional de México, s.f.) bajo la misma metodología, presenta paisajes sonoros de diferentes ciudades del mundo a partir de la captura del instante por medio del sonido y la fotografía.

En el campo de los mapas sonoros, la investigación Sobre cartografías sonoras urbanas de Berrens (2014), combina la experiencia en trabajo de campo, con una reflexión que surge de la revisión de proyectos desarrollados bajo el tema de los paisajes sonoros, que además es comparada con los postulados de diferentes autores, de esta manera, se plantea una concepción global del tema de las percepciones y los paisajes sonoros en el contexto urbano y su relación con la construcción de lugar, respecto a las percepciones sonoras, la autora se refiere a particularidades del sonido como la constancia y continuo cambio del mismo, asimismo, reflexiona sobre el hecho de que no somos capaces de cerrar los oídos como sí cerramos los ojos, por esto, el sonido constituye una atmósfera que constantemente hace parte de la experiencia como ciudadanos. De esta manera, se define que la relación entre el sonido y la percepción del lugar está ligada al espacio físico y los desplazamientos del ciudadano. Es decir que el sonido, también influye en el comportamiento del ciudadano y condiciona dinámicas y desplazamientos por algunos lugares u otros, influye en la comprensión y relación con el espacio.

En Colombia, la Fonoteca Nacional ha emprendido el proyecto Mapa sonoro de Colombia, el cual, se ha propuesto desarrollar un mapa de los sonidos del país; para ello, ha desarrollado una plataforma virtual (Radio Nacional de Colombia, s.f.) en la que existe una convocatoria abierta para publicar registros de sonidos captados en el territorio colombiano, que dan cuenta de la cotidianidad, el contexto geográfico y las costumbres de los colombianos. Como respuesta a este llamado, se planteó el proyecto 200 efectos de sonidos urbanos de la ciudad de Bogotá realizado por Edgar Castro (2013), en el que se determina que los "sonidos identifican una sociedad y sus costumbres, un tiempo y un espacio, puesto que la información sonora registrada es única, teniendo en cuenta que los sonidos varían a través de los años por cambios en el medio ambiente, en la movilidad, en la industrialización y todas las demás transformaciones propias de una ciudad (Señal Colombia Sistema de Medios Públicos, 2013).

De manera similar, se desarrollan los trabajos del colectivo Sonema (2013), grupo que se dedica al fomento de la experimentación y exploración sonora, también en la ciudad de Bogotá y que, en Bogotá Fonográfica (2013), propone un mapa sonoro de la ciudad que se alimenta del trabajo colaborativo y la creación colectiva con el objetivo de recopilar el patrimonio sonoro de la ciudad, así pues, registra sonidos de la cotidianidad capitalina y los ubica espacialmente en el mapa.

Este tipo de estudios, así como las experiencias referenciadas a lo largo del documento, se caracterizan por ser muestras espacio-temporales de la imagen de la ciudad, compuestas por las manifestaciones urbanas de tipo visual, sonoro, olfativo, táctil y del gusto que constituyen, más allá de lecturas de la ciudad, formas de reconocimiento del valor patrimonial intangible de las ciudades.

\section{Aproximación teórica: Ciudad en perspectiva}

La ciudad como objeto de investigación ha sido abordada desde múltiples miradas, especialmente, a partir de la segunda década del siglo XX el espacio urbano se constituye como el principal hábitat contemporáneo. 
Desde la estética se han realizado investigaciones que nos han permitido comprender la ciudad más allá de la morfología, densidad, entre otros aspectos, es este marco en el que se plantea la ciudad como un objeto de estudio, en la que la percepción, los sentidos, los imaginarios, la comunicación y la visualidad han permitido diferentes acercamientos para comprender a la ciudad como red de comunicación.

\section{Imaginarios urbanos y la imagen de ciudad}

Imaginario y ciudad presentan una relación tautológica, la existencia en el organismo denominado ciudad supone de hecho que quienes habitan la ciudad generen una serie de relaciones que van más allá de los desplazamientos y las permanencias, ya que la ciudad no es hecho estático e inerte, crece, evoluciona, crea, promueve, acepta y rechaza, esas relaciones son los imaginarios, de manera que "los imaginarios son aquellas ideas o elementos referenciales que expresan anhelos o frustraciones de una comunidad determinada y que nos hablan de lo deseado y lo querido" (Rincón, 2001, p. 20).

Los imaginarios son construcciones mentales humanas sobre el espacio que se habita, pueden ser de carácter individual, pero su vitalidad es aún mayor cuando son de carácter colectivo. Los imaginarios son resultado de las prácticas sociales, evolucionan constantemente, se hacen y también se deshacen, son eliminados u olvidados. Los imaginarios más potentes son aquellos cuyas raíces están íntimamente ligados a eventos o acontecimientos muy asimilados socialmente, por ejemplo, los imaginarios de carácter religioso, otros se conforman a partir de la historia y la tradición, otros más recientes a través de decisiones político administrativas, otros por impactantes realidades cotidianas, por tanto "los imaginarios sociales son la realidad urbana construida desde los ciudadanos" (Silva, 2003, p. 24).

La ciudad como organismo social, es una de las principales productoras de imaginarios, son los llamados imaginarios urbanos, estos entonces se entienden como las construcciones que realizan los habitantes de la ciudad, son ideas y percepciones sobre el espacio urbano, entendiendo ese espacio no solo en términos físicos, sino y especialmente en términos simbólicos.

Los imaginarios urbanos constituyen una de las formas de evidenciar las relaciones de los ciudadanos con su entorno, además estos se relacionan con códigos y símbolos que permiten comprender el entorno urbano y dan significado a ciertas prácticas sociales, de manera que:
Estos tres tipos de elementos (símbolos, códigos e imaginarios) no son estáticos y tienen condicionamiento de tiempo y lugar. Tampoco se presentan de forma separada en la vida real (un imaginario puede expresarse a través de un símbolo y este puede tener relación directa con una serie de códigos, etc.). (Niño, Torres, Mendoza, Echeverría y Gaitán, 1998, p. 2).

En la ciudad, es importante entender que los imaginarios tienen proyecciones visuales, es lo que se comprende como expresiones físicas de los imaginarios, esto quiere decir que muchas de las relaciones visuales que el habitante establece con la ciudad son producto de los imaginarios, por ejemplo: los enrejados, la pintura, la composición de las fachadas, la gráfica popular comercial, la manera de apropiarse del espacio, entre otras. Los imaginarios casi siempre están mediados por aspectos de carácter simbólico, es decir los imaginarios existen porque brindan significado al espacio contemporáneo por excelencia: la ciudad; de otro lado los imaginarios,

Determinan maneras de ser y comportarse, así como las formas de uso de los objetos que representan. En esta medida, los imaginarios no existen en un espacio geográfico, sino simbólico, que permite rastrear y examinar posiciones y relaciones inter-subjetivas y ecológicas. A su vez, los objetos que incorporan imaginarios van construyendo archivos que, más allá de almacenar cosas tangibles, van almacenando experiencias estéticas y valoraciones simbólicas. Dichos archivos sirven para jerarquizar y valorar culturalmente los objetos y sus imaginarios. En este sentido, mientras que lo imaginario hace alusión a la percepción grupal a través de los deseos, el archivo implica su documentación, almacenamiento y reconocimiento. Los imaginarios apuntan a una categoría cognitiva que revela cómo los seres sociales, no por medio de la razón, sino más bien a través de la sensación perciben sus propios mundos y realidades. (Silva, 2012)

Los imaginarios urbanos, si bien pueden detectarse a partir de fragmentarlos en percepciones particulares, siempre se reflejarán en expresiones colectivas (Silva, 2003, p. 103), pues estos parten de deseos y ambiciones colectivas, que los ciudadanos interiorizan y con los cuales se ven reflejados como colectivo en sus tradiciones urbanas. Las tradiciones urbanas no son más que el reflejo de los imaginarios sociales, de cómo el ciudadano percibe su ciudad, "son evocaciones 
ciudadanas, los modos como las personas se imaginan sus actividades diarias" (Silva, 2003, p. 113), estas tradiciones urbanas se ven reflejadas con frecuencia en la realización de eventos, y denotan además subestéticas que proyecta la comunidad en los actos públicos. Todos estos acontecimientos se cargan de un valor emocional notable y dan cuenta de la cultura popular urbana, es decir, contienen un carácter simbólico y establecen desde los espacios físicos una narrativa del paisaje urbano puesto que, "no se trata de hablar de objetos y espacios como piezas sueltas, sino más bien de ver y mostrar cómo se tejen, alrededor de estos territorios, visiones del mundo muy diversas." (Popular de Lujo, 2005, p. 2). Los imaginarios como construcción colectiva configuran la noción del lugar, lugar habitado, en este caso: la ciudad, y se entretejen de identidad, tradiciones, deseos y experiencias.

Aunque la ciudad no es algo que necesariamente está ausente, aun así, por la magnitud física de la misma todo ciudadano requiere formar en su mente una idea, una imagen mental (Lynch, 1984) que le permita comprender el espacio que habita; la existencia de mapas, fotografías y demás, evidencian la necesidad de generar imágenes de la ciudad, sean estas de carácter cartográfico y geográfico que en muchos casos adquieren un carácter abstracto pues siempre ofrecen una visión bidimensional de la ciudad, o sean estas parte de los imaginarios individuales y colectivos, es decir otro tipo de imágenes, que abarcan ideas, percepciones, sensaciones, entre otras, en todo caso "una imagen es genuinamente simbólica por su propia estructura" (Pérgolis, 1998, p. 72)

La imagen de la ciudad se construye a partir de categorías que tienen que ver tanto con los aspectos visibles de la misma, como con aquellos que se forman en la mente de los ciudadanos; en los dos casos intervienen aspectos históricos, morfológicos, físicos, culturales, estéticos, simbólicos; así una imagen básica es la ofrecida por el mapa y sus transformaciones gráficas a través del tiempo, también está la imagen de la ciudad desde su conformación física, su dinámica socioeconómica, su noción de progreso, estas imágenes alimentan y configuran diferentes percepciones en el ciudadano, así mismo la ciudad como hecho espacial y de interacción cotidiana entre lo físico y lo humano y en la cual el ciudadano hace sus intervenciones y en donde el ente administrativo como 'acto' político también ejerce su poder de intervención (infraestructura, equipamiento, espacio público, entre otros) promueve la creación de una imagen que se mueve entre los términos de lo funcional hasta lo estético, de manera que: "la imagen urbana no pertenece a la ciudad sino a sus habitantes ya que es el modo como los ciudadanos la representan en su mente; por eso, la imagen identifica a la ciudad, no por cómo es sino por cómo es vista" (Pérgolis, 1998, p. 2)

A la vez las imágenes urbanas son, según Pérgolis, “imágenes emocionalmente nítidas y fácilmente interiorizables, es decir como partes independientes autónomas en sí mismas, equivalentes entre sí y sin pretensiones de reconstrucción de la totalidad urbana." (1998, p. 72); la imagen que se produce desde la intervención es la imagen que proyecta la ciudad, "así, cada ciudad tiene unas estéticas que nacen de las proyecciones de sus habitantes" (Silva, 2003, p. 81) por otra parte, está la imagen de ciudad que se conforma a partir de los imaginarios colectivos, esa otra imagen que no es física en un mapa, que no es construida mediante intervenciones sino es aquella imagen simbólica, percibida y expuesta por el colectivo o bien sea inventada para algo. Todas estas visiones conforman la idea de ciudad, de los que la habitan, de los que la ven de lejos, de los que la usan y de los que a veces la aman y por tanto se puede entender a "la imagen urbana como la síntesis de la relación entre las identidades cultural y espacial" (Pérgolis, 1998, p. 8). En consonancia con lo anterior, Lynch argumenta que:

Todo ciudadano tiene largos vínculos con una u otra parte de su ciudad, y su imagen está embebida de recuerdos. El propio observador debe desempeñar un papel activo al percibir el mundo y tener una participación creadora en la elaboración de su imagen. Debe contar con el poder de cambiar esa imagen para adaptarse a necesidades cambiantes. (1984, p. 9)

En este sentido la relación habitante lugar esta mediada por la imagen, en la que el ciudadano es participe, co-creador, desencadenador, que tamiza y produce las narrativas que dicha imagen pueda significar, por tanto, para comprender una imagen ambiental, Lynch propone tres ámbitos de análisis: la identidad, la estructura y el significado de manera que:

Una imagen eficaz requiere, en primer término, la identificación de un objeto, lo que implica su distinción con respecto a otras cosas, su reconocimiento como entidad separable. A esto se le da el nombre de identidad, no el sentido de igualdad con otra cosa sino con el significado de individualidad o unicidad. [...] la imagen debe incluir la relación espacial o pautal del objeto con el observador 


\section{Imaginario}

Construcción colectiva de significados

sobre el lugar. Se componen de identidad,

prácticas, tradiciones, anhelos, experiencias, rumores

\section{Acontecimiento}

Práctica social en el espacio físico (espacio público)

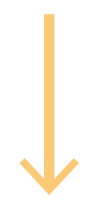

\section{Imagen del lugar}

Imagen mental común de los ciudadanos

\section{Espacio público}

Redes de sociabilidad, comunicación e interacción superpuestas que transcurren en el espacio físico
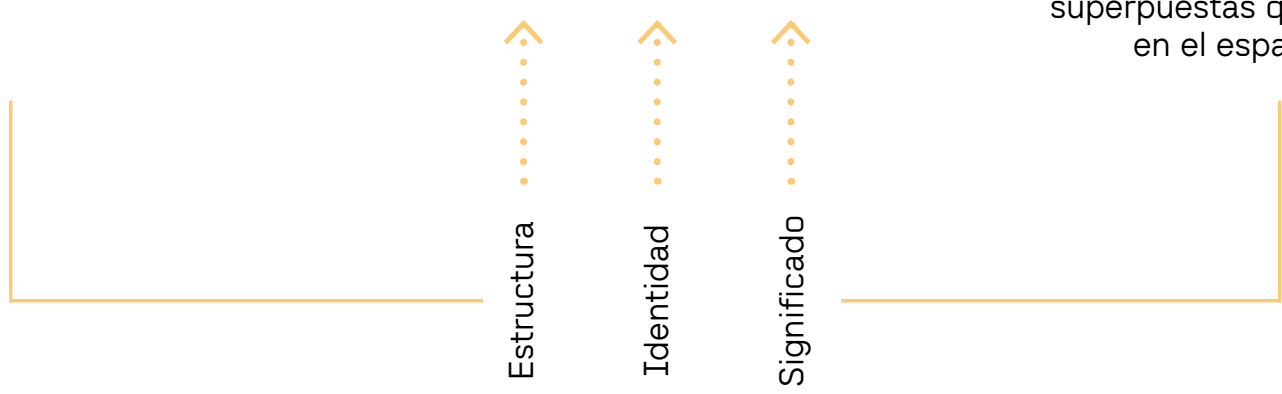

Gráfica 2. Proceso de construcción de la imagen de la ciudad. Fuente: Guerrero (2015).

y con otros objetos. Por último este objeto debe tener cierto significado, práctico o emotivo, para el observador, el significado es así mismo una relación, pero se trata de una relación completamente diferente a la espacial o pautal. (1984, p. 17)

En todo caso la imagen urbana no solo está relacionada con la percepción, como la resultante primaria de una serie de estímulos, es en esencia un enunciado del conocimiento que los seres humanos expresamos intelectualmente. (Batro y Ellis, 1999), de manera que "la imagen de ciudad estaría definida como la imagen mental que el ciudadano construye de la ciudad que habita" (González, 2004) y que contempla entre otros, aspectos relativos a la representación, es decir, atributos y características otorgados por los habitantes a la identidad, es decir la distinción de la misma como una unidad separada de otras, esta identidad no solo se revela a través de evidencias físicas, sino que tal identidad puede ser también emocional, es decir la imagen de la ciudad es también una prosopeya; puede hablarse también de una imagen construida esencialmente de recorridos, pues esa experiencia vital del transeúnte (Joseph, 2001), es una de las que con mayor facilidad permite organizar las imágenes de ciudad y por supuesto, está relacionado con los valores simbólicos que se le otorgan a la ciudad.
Una de las formas más prácticas de análisis en términos de identificación de categorías en la construcción de la imagen mental de las ciudades, es la de Kevin Lynch (1984), que incluye el reconocimiento de bordes, sendas, nodos, barrios y mojones.

Finalmente, se puede establecer que una imagen urbana se entiende entonces desde dos aspectos fundamentales, el primero se relaciona con los elementos, las lecturas físicas de la ciudad y las construcciones visuales: forma, extensión, tamaño, altura, incluyendo aspectos geográficos como el clima, la topografía, entre otros; y manifestaciones visuales como el tratamiento de las fachadas, la gráfica y el espacio público; el segundo desde los aspectos imaginados, es decir las lecturas de la ciudad desde las ideas y percepciones de los habitantes, por ejemplo definir una ciudad como tranquila, es parte del imaginario y es un aspecto que no puede encontrarse a nivel físico, definir una ciudad como lineal, es un concepto asociado a un elemento netamente físico, de manera que "existe una estrecha correlación entre identidad cultural e identidad espacial, que la sociedad para su coherencia necesita integrar en la imagen de la ciudad" (Pérgolis, 1990, p. 25), siendo así la identidad de la ciudad de acuerdo con Pérgolis, se comprende entonces como un "cruce de redes y superposición de fragmentos culturales" (1998, p. 14). 


\begin{tabular}{|c|c|c|c|}
\hline Investigador & $\begin{array}{l}\text { Caracterización } \\
\text { de la imagen subjetiva }\end{array}$ & $\begin{array}{l}\text { Caracterización } \\
\text { de la imagen física }\end{array}$ & Determinantes del mapa \\
\hline Lynch Kevin & $\begin{array}{l}\text { Identidad } \\
\text { Estructura } \\
\text { Significado }\end{array}$ & $\begin{array}{l}\text { Nodos, sendas, hitos, } \\
\text { bordes, barrios }\end{array}$ & $\begin{array}{l}\text { Legibilidad-probabilidad de } \\
\text { suscitar una imagen }\end{array}$ \\
\hline Klein H.J. & $\begin{array}{l}\text { Percepción del "centro" } \\
\text { frente a la imagen total de } \\
\text { la ciudad }\end{array}$ & $\begin{array}{l}\text { Estructura topográfica } \\
\text { Estructura funcional }\end{array}$ & $\begin{array}{l}\text { Relación centro-vivienda } \\
\text { tiempo de residencia, profesión } \\
\text { y genero determinan la imagen }\end{array}$ \\
\hline Appleyard & $\begin{array}{l}\text { Estilos cognitivos: } \\
\text { Secuenciales } \\
\text { Espaciales }\end{array}$ & $\begin{array}{l}\text { Elementos propuestos } \\
\text { por Lynch }\end{array}$ & $\begin{array}{l}\text { Familiaridad, tiempo de } \\
\text { residencia, zonas de uso } \\
\text { (vivienda, trabajo), formas de } \\
\text { desplazamiento }\end{array}$ \\
\hline Goodey & $\begin{array}{l}\text { Imágenes primarias: } \\
\text { experiencia con el } \\
\text { ambiente } \\
\text { Imágenes secundarias: } \\
\text { medios de comunicación } \\
\text { y contactos }\end{array}$ & Ambiente construido & $\begin{array}{l}\text { Las conductas determinan el } \\
\text { mapa }\end{array}$ \\
\hline Milgram & Ciudad=hecho social & $\begin{array}{l}\text { Reconocimiento objetos } \\
\text { físicos de la ciudad }\end{array}$ & $\begin{array}{l}\text { Centralidad y características } \\
\text { sociales } \\
\text { y/o arquitectónicas }\end{array}$ \\
\hline Kaplan & $\begin{array}{l}\text { Reconocimiento } \\
\text { Predicción } \\
\text { Evaluación } \\
\text { Acción }\end{array}$ & $\begin{array}{l}\text { Coordenadas } \\
\text { espacio-temporales }\end{array}$ & $\begin{array}{l}\text { Los dominios de } \\
\text { procesamiento corresponden } \\
\text { a las formas de contacto con } \\
\text { el ambiente }\end{array}$ \\
\hline Moore & Aspectos individuales & $\begin{array}{l}\text { Jerarquías, diferencias } \\
\text { y relaciones }\end{array}$ & $\begin{array}{l}\text { El desarrollo formal del mapa } \\
\text { es coherente con el grado de } \\
\text { familiaridad de los sujetos } \\
\text { con la ciudad: } \\
\text { Nivel I: Egocéntrico } \\
\text { e indiferenciado } \\
\text { Nivel II: Diferenciado y } \\
\text { parcialmente coordinado } \\
\text { Nivel III: Abstractamente } \\
\text { coordinado y jerárquicamente } \\
\text { coordinado }\end{array}$ \\
\hline $\begin{array}{l}\text { Holohan y } \\
\text { Drobrowdlny }\end{array}$ & $\begin{array}{l}\text { Conducta individual y } \\
\text { colectiva del ambiente }\end{array}$ & Límites, formas, centro & $\begin{array}{l}\text { Diferencias individuales en } \\
\text { la conducta personal del } \\
\text { ambiente }\end{array}$ \\
\hline
\end{tabular}

Tabla 1. Resumen de las investigaciones relacionadas con la imagen de la ciudad y los mapas cognitivos. Fuente: Autores con base en la revisión de Aragonés (1983). 
De tal manera se puede observar que la imagen de la ciudad, se nutre de acontecimientos, imaginarios y hechos físicos, y que está caracterizada por un tejido de identidades, y significados y que en esa construcción es posible encontrar sistemas de códigos y símbolos que permiten armar nociones de territorio amplias y convergentes.

Yori, equipara en últimas, la imagen de la ciudad con el concepto alemán de Raumqeist: es decir como el "conjunto de relaciones físico ambientales y psíquico-sociales que hacen de un lugar un acontecimiento físico-cultural" (1999, p. 329).

\section{Cartografías y nuevas dimensiones de la ciudad}

La comprensión de la imagen de la ciudad a través de los mapas cognitivos comprende estudios desde hace cerca de 50 años, desde la investigación de Lynch en los años 60, una serie de teóricos del urbanismo, la geografía y la psicología se han dado a la tarea de probar metodologías aptas para el estudio de las ciudades.

Aragonés, (1983) hace una extensa revisión de las investigaciones realizadas en Europa y Estados Unidos, buscando ofrecer un marco de referencia que relaciona mapas e imagen de ciudad. A continuación se resume los aspectos fundamentales que apuntan a determinar los aspectos que históricamente se han validado en este tipo de estudios:

De esta manera, es posible determinar que la interacción ciudadano-ciudad, está en gran parte dada por la existencia de un mapa cognoscitivo o del conocimiento que tiene el ciudadano por la ciudad. Este representa la forma en la que el ciudadano capta, sintetiza, estructura y almacena la información que posee del espacio y que le permite moverse e interactuar dentro de la ciudad. En muchos casos los mapas llegan a ser similares entre los ciudadanos, de acuerdo al lugar donde viven, estudian o trabajan, sin embargo, los mapas mentales nunca son colectivos, cada persona organiza de forma individual en su mente la ciudad de acuerdo a sus preferencias, Valencia (2009) considera que este tipo de cartografía está constituida por:

Mapas que nos hablen por ejemplo de la vida cotidiana que desarrollamos, de los itinerarios y recorridos, de los eventos urbanos, de aquello que no sólo está estático, de lo que no está lleno, de lo que sucede en simultáneo, de lo híbrido, de lo que está al margen, de lo que no es central, de todo aquello que está soterrado en los rincones físicos y temporales de las urbes a las que pertenecemos. (p. 2)

Entonces, un mapa cognoscitivo básicamente se forma por acción de la cotidianidad, cada persona representa sus recorridos diarios y los lugares que frecuenta, como lo postula Bazant (2008) "un mapa cognoscitivo no es un plano que duplica como fotografía el mundo real, sino más bien es un conjunto de información abstracta y muy selectiva representado en una diversidad de formas" (p. 30), lo cual indica que el mapa mental no es comparable con el mapa cartográfico, pues este presenta vacíos de información, incongruencias con la realidad y acomodación subjetiva de la información. De esta manera, es posible interpretar la herramienta de la cartografía como aquella que,

Permite, entonces una nueva manera de entender el lugar. De codificar lo real no como una lectura lineal sino como una interpretación de capas superpuestas [...] que busca detrás de cada imagen hallar otras imágenes [...] la cartografía opera como una forma de interpretar la ciudad textualmente, es decir identificando sus narrativas y relatos, sus lógicas simbólicas y sígnicas, sus campos discursivos. (Valencia Palacios, 2009, p. 7)

Existen diferentes tipos de mapas mentales de acuerdo a la forma en que es configurada la información, en algunos casos se presentan mapas mentales de recorrido que especifican los recorridos, rutas y sendas que, sigue la persona en la ciudad, los mapas mentales fragmentados que señalan lugares sin conexión entre ellos, los mapas mentales bien configurados que demuestran un amplio conocimiento de la ciudad y los mapas mentales desvirtuados que están configurados de una forma muy lejana a la realidad.

Por otra parte, están los mapas culturales que, a diferencia de los cognoscitivos, son construcciones colectivas en las que además del conocimiento por la ciudad intervienen otros aspectos relacionados con la experiencia de los ciudadanos, estos son "representaciones gráficas de características físicas de un territorio o de hechos que ocurren en su interior" (Mejía, 2001, p. 14). En general estos mapas representan características específicas del territorio, referidos a acontecimientos culturales, su configuración depende del propósito social que se persiga, pues sus objetivos pueden estar enfocados hacía la representación de imaginarios urbanos, de apropiación del espacio, de expresiones subjetivas, de rescate de valores y tradiciones y de encontrar 
valores significativos de los hechos que ocurren en tales territorios. En los mapas culturales explica Mejía:

La dimensión temporal $\{\ldots\}$ cobra importancia según sea la dinámica de lo representado en ellos, y los hechos sociales, a los que corresponden las culturas, son permanentemente cambiantes, de manera especial en nuestra época y en nuestro medio, sin que ello signifique que deban tener estos mapas un carácter apenas coyuntural, aunque el momento en que se realicen les imponga su sello. Inclusive yendo a más detalle, hay algunos hechos a consignar en un mapa que son sensibles a la hora del día de la semana, pensamos, como ejemplo, en el uso del espacio público (2001, p. 14).

Los mapas culturales son una especie de radiografía del momento del territorio, pues cambian, evolucionan y crecen, lo realmente valioso es que permiten identificar dentro del espacio estudiado, elementos, sensaciones y percepciones, que no suelen ser tan evidentes. De ahí que "sean herramientas útiles para la compresión de realidades sociales, geográficas e históricamente determinadas, cada mapa tiene la marca del tiempo y el espacio que se mira y del momento y el sitio desde el que se miran, además del propósito de la mirada." (Mejía, 2001, p. 17). En los mapas culturales fácilmente se pueden expresar e identificar los símbolos, códigos e imaginarios conexos a una noción de territorio para comprender en el momento especifico la realidad cultural presente (Rincón, 2001, p. 20). Y ya que el territorio es "un escenario que reproduce relaciones sociales de valores, de poder, de prestigio, de parentesco, de acuerdo con el grupo social al que está circunscrito. Este fenómeno tiene su presencia en la vida cotidiana de gran parte de la población. "Los escenarios de prácticas territoriales, como los barrios, permiten interpretar, y dar cuenta de importantes dinámicas sociales". (González, 2001, p. 35)

De igual forma, la ciudad se compone de fragmentos, que terminan configurando micro territorios, no solo espacial, sino simbólica y culturalmente, así un parque, una calle, incluso una esquina, es susceptible de ser analizada como fragmento tanto como sectores más amplios como los barrios. Es así como la cultura y "su estudio en la cotidianidad misma del comportamiento y acción ciudadana, donde las significaciones y mundos simbólicos, las identidades, las fragmentaciones, relacionamientos, diferencias y conflictos, se "materializan" se hacen evidentes y aprehendibles, y pueden contribuir a pensar la ciudad a partir de sus fragmentos y diferencias". (Niño, et.al., 1998, p. ix), de acuerdo con estos autores un mapa cultural como herramienta y producto,

Codifica y localiza sobre el territorio los elementos que mediatizan las relaciones de los grupos y sectores sociales consigo mismos, con sus semejantes o con algunos elementos de su entorno. Esto es tratar de ubicar sobre un plano cartográfico, la distribución especial que en la vida cotidiana tienen códigos, símbolos e imaginarios, explicando el significado y determinando la prioridad que, para los grupos y sectores sociales en cuestión, tienen cada uno de los elementos identificados. (1998, p. 2)

Así, la noción cartográfica resulta ser un espacio de narrativa social y no solo de expresión visual.

\section{La ciudad territorio de imaginarios y significados}

La ciudad se concibe a partir de diversas perspectivas como espacio de significados, como objeto estético, como espacio sensorial, como patrimonio, como red de comunicación, entre otras. Todas esas formas de interpretación, conforman lo que llamamos territorio construido, y ese tejido hace parte de la construcción mental que se evidencia desde la percepción, en la cual intervienen la interacción de los sentidos, el contexto físico y apropiación simbólica.

Cuando esas interacciones dejan de ser individuales y se comparten, se convierten en imaginarios urbanos, estos conllevan a que se establezca temporalmente una imagen de la ciudad, que finalmente, lleva a reconocer las nociones de territorio a manera de nuevas y diversas cartografías.

\section{Referencias}

Altamirano, L. (14 de enero de 2013). Paisajes sonoros de los barrios de ciudad de México. Bifurcaciones: Revista de Estudios Culturales Urbanos.

Aragonés, I. (1983). Marcos de referencia en el estudio de los mapas cognitivos de ambientes urbanos. estudios de Psicología (14/15), p. 36. DOI: https://doi. org/10.1080/02109395.1983.10821353

Auge, M. (1993). Los no lugares. Espacios del anonimato. Barcelona: Gedisa.

Barbosa, L. J., Velázquez Osorio, J. y Suárez Quintero, S. (2012). "Entre lo Puro e Impuro: Representaciones 
Iconográficas en Bogotá." En L. J. Barbosa, J. Velázquez Osorio, S. Suárez Quintero, P. Carvajal, P. Cervantes, S. Rueda Fajardo, y otros. Conversaciones acerca de la fotografía, pp. 12-16. Tunja: Ediciones Universidad de Boyacá.

Batro, A. y Ellis, E. (1999). La imagen de la ciudad en los niños. Recuperado de Batro\&Denham: http://www.byd. com.ar/ciudad5.htm, (20 de febrero de 2007).

Bazant, J. (2008). Espacios Urbanos, Historia, Teoría y Diseño. México: Limusa.

Berrens, K. (2014). Sobre Cartografías Sonoras Urbanas. Bifurcaciones: Revista de estudios culturales urbanos(18).

Boeri, C. (2010). "A perceptual approach to the urban color reading." En P. Zennaro, Color and Light in Architecture, pp. 459-463. Verona: Knemesi.

Castro Herrera, E. (2013). 200 Efectos de sonidos urbanos de la ciudad de Bogotá. Universidad El Bosque, Formación musical. Bogotá: Universidad El Bosque.

Colectivo Sonema. (2013). Bogotá Fonográfica. (Registro sonoro). Bogotá: Laguna Libros.

Echeverri Arango, N. (2007). Expresiones estéticas del hábitat dentro de una comunidad barrial en transformación: La Piel del Morro. Medellín: Universidad Nacional de Colombia, Sede Medellín.

El Tiempo - Zona. (2014). El Tiempo. Recuperado el 15 de noviembre de 2015, de ¿A qué huele Bogotá? https://app.eltiempo/multimedia/ infografias/a-que-huele-bogota/14672083

Fonoteca Nacional de México. (s.f.). fonotecanacional. Recuperado el 20 de marzo de 2014, de http://www. fonotecanacional.gob.mx/ el

García Canclini, N. (2010). De la comida al monumento: lo intercultural más allá de los rituales. Recuperado el 9 de julio de 2013, de http://nestorgarciacanclini.net/ index.php?option=com_content\&view=article\&id $=130$ : de-la comidangc\&catid=36:estetica-yantropologia\&Itemid $=56$

Goldaracena, D. (2013). Daniel Goldaracena. Recuperado el 25 de octubre de 2013, de Book of sounds: http:// danielgoldaracena.com el
González, C. (2001). "El mapa cultural desde la mirada antropológica." En C. González, Memorias Urbanas. Pereira: Haciendo ciudad desde los mapas culturales, pp. 32-45. Pereira: Instituto de Cultura de Pereira.

González, P. (2004). Imágenes de ciudad: Percepción y cognición en niños de Bogotá. Bogotá: Alcaldía Mayor de Bogotá. Instituto Distrital de Cultura y Turismo Observatorio de Cultura Urbana.

Guerrero, Y. (2012). De la ciudad me sé su olor: Aproximaciones visuales y otros sentidos / Tunja. Tunja: Ediciones Universidad de Boyacá.

Hamann, H. (2001). New York Vertical. Mannheim, Alemania: Edition Panorama. DOI: https://doi. org/10.1126/science.291.5505.827B https://doi.org/10.1021/bi002231o https://doi.org/10.1021/bi002836k

Joseph, I. (2001). El transeúnte y el espacio urbano. Barcelona: Gedisa.

Kogan, J. (1986). Filosofía de la imaginación. Barcelona: Paidós Studio.

Lenclos, J. (1999). Colors of The World. París, Francia: W.W. Norton \& Company Inc.

Lynch, K. (1984). La imagen de la ciudad (10a tirada 20121 ed.). Barcelona: Gustavo Gilli.

Mc Lean, K. (2014). Smell Map Narratives of Place Paris. NANO New American Notes Online(6).

Mejía, W. (2001). "Acerca de las mapas culturales." En C. Gónzalez, Memorias Urbanas. Pereira: Haciendo ciudad desde los mapas culturales, pp. 7-19. Pereira: Instituto de Cultura de Pereira.

Meléndez, M. (2012). "Análisis iconográfico del almuerzo popular "corrientazo" en la ciudad de Bogotá a partir de los conceptos percepto y afecto de Gilles Deleuze." En S. i. Unitec, Memorias 2 Encuentro interdisciplinario de grupos de investigación. Arte, ciencia, tecnología e innovación, pp. 41 - 64. Bogotá, Colombia: Centro de publicaciones académicas Unitec.

Miralda, A. y Guillén, M. (2011). www.foodcultura. org. Recuperado el 9 de julio de 2013, de http://www. foodcultura.org/ 
Montañez, G. (2002). Pensar la ciudad. En C. A. Torres Tovar, La ciudad: Hábitat de diversidad y Complejidad, pp. 22-38. Bogotá D.C: Unibiblos Universidad Nacional de Colombia.

Montoya, J. (2000). "De las memorias a las dramaturgias urbanas." En U. Nacional, Cultura y Región (pp. 293314). Bogotá: Ministerio de Cultura/Centro de Estudios Sociales Facultad de Ciencias Humanas Universidad Nacional.

Museo de Bogotá. (2005). Paul Beer Metamorfosis de una ciudad. Bogotá: Alcaldía Mayor de Bogotá, Instituto Distrital de Cultura y Turismo.

Niño, C., Torres, M. C., Mendoza, D. M., Echeverría, S. y Gaitán, J. C. (1998). Usos, costumbres e imaginarios en el espacio público: El Sector de Jerusalén. Bogotá: Observatorio de Cultura Urbana.

Noguera, P. (2004). El reencantamiento del mundo. Manizales: Universidad Nacional de Colombia. IDEA.

Páez, A. y Hernández, C. (Mayo de 2014). Son tus aromas: Bogotá. Nota Uniandina(43), pp. 2-4.

Pérgolis, J. C. (1990). Formas, Usos y Significaciones de las plazas en Colombia y América Latina. Escala (151), pp. 4-36.

Pérgolis, J. C. (1998). Bogotá Fragmentada. Cultura y Espacio Urbano a fines del siglo XX. Bogotá: T/m editores.

Popular de Lujo. (2000). Eres lo que comes. (D. F. Valencia, Ed.) Recuperado el 9 de agosto de 2013, de Popular de Lujo: www.populardelujo.com

Popular de Lujo. (2000). Mesa 19. Recuperado el 9 de agosto de 2013, de Popular de Lujo: www.populardelujo.com

Popular de Lujo. (2000). Popular de Lujo. Recuperado el 9 de agosto de 2013, de www.populardelujo.com

Popular de Lujo. (2005). Ciudad (in) visible. Gráfica e iconografía popular urbana. Bogotá: Alcaldía Mayor de Bogotá. Instituto Distrital de Cultura y Turismo.

Radio Nacional de Colombia. (s.f.). senalmemoria. Recuperado el 15 de marzo de 2014, de Radio Nacional: http://www.senalmemoria.gov.co
Rincón, M. (2001). Mapas Culturales. En C. Gonzalez, Memorias Urbanas. Pereira: Haciendo ciudad desde los mapas culturales. Pereira: Instituto de Cultura de Pereira.

Rodríguez, C. (2014). ¿De qué color son las ciudades? Metodologías de apreciación cromática urbana. Revista Designia, 2(2), pp. 14-34.

Ross, F. (2014). Paisajes sensoriales: sensación y emoción en el hacer del lugar. Bifurcaciones: Revista de Estudios Culturales Urbanos(16).

Salas, C., Ávila, J. y Quiroz, F. (2003). Bogotá, cinco sentidos. Bogotá, Colombia: Fuga editores.

Señal Colombia Sistema de Medios Públicos. (06 de junio de 2013). Señal Memoria. Obtenido de 200 sonidos urbanos de la ciudad de Bogotá estarán en el Mapa Sonoro: http://www.senalmemoria.gov.co/index. php/home/actualidad/item/936-200-sonidos-urbanosde-la-ciudad-de-bogotá

Silva, A. (2002). "Ciudadano, Mente y Tecnología." En C. A. Torres Tovar, La ciuada: hábitat de diversidad y complejidad, pp. 100-125. Bogotá D.C: Unibiblos Universidad Nacional de Colombia.

Silva, A. (2003). Bogotá Imaginada. Bogotá, Colombia: Taurus.

Silva, A. (2012). Imaginarios urbanos. Recuperado el 28 de septiembre de 2015, de http://www. imaginariosurbanos.net

Sonema. (2013). Sonema. Recuperado el 8 de noviembre de 2013, de http://www.sonema.org

Valencia Palacios, M. (2009). Cartografías urbanas. Imaginarios, huellas, mapas. Revista electrónica DU\&P. Diseño Urbano y Paisaje, 5(16), pp. 1-17.

Velázquez Osorio, J. (octubre de 2010). www. julianvelasquez.com. Recuperado el 5 de julio de 2013, de Metáforas e íconos de la carne en Bogotá: www. julianvelasquez.com/wp-content/uploads/2010/09/ METÁFORAS-E-ICÓNOS-DE-LA-CARNE-EN-BOGOTA.pdf

Yori, C. M. (1999). Topofilia o la dimensión poética del habita. Bogotá: Pontificia Universidad Javeriana. CEJA. 
